\title{
Comparative Life Cycle Assessment of Bioenergy Production from Different Wood Pellet Supply Chains
}

\author{
Andrea Sgarbossa ${ }^{1}\left(\mathbb{D}\right.$, , Martina Boschiero ${ }^{1, *}$, Francesca Pierobon ${ }^{2, *}$, Raffaele Cavalli ${ }^{1}(\mathbb{D}$ and \\ Michela Zanetti ${ }^{1}$ (I) \\ 1 Department of Land, Environment, Agriculture and Forestry, Università degli Studi di Padova, \\ Viale dell'Università 16, 35020 Legnaro, Padova, Italy; andreasgarbossa@gmail.com (A.S.); \\ raffaele.cavalli@unipd.it (R.C.); michela.zanetti@unipd.it (M.Z.) \\ 2 School of Environmental and Forest Sciences, University of Washington, Seattle, WA 98195, USA \\ * Correspondence: martina.boschiero@unipd.it (M.B.); pierobon@uw.edu (F.P.); Tel.: +39-049-8272726 (M.B.); \\ +1-206-616-3681 (F.P.)
}

Received: 2 September 2020; Accepted: 19 October 2020; Published: 23 October 2020

check for updates

\begin{abstract}
The EU is one of the largest producers and consumers of wood pellets in the world, covering around $36 \%$ of the global wood pellet production and around $50 \%$ of the global consumption in 2018. The EU wood pellet consumption is expected to further increase in response to the ambitious energy and climate goals for 2030. Currently, wood pellets are mainly produced from sawdust and other sawmill residues; however, other types of forest feedstock are being investigated in order to meet the increasing wood pellet demand and move toward greater energy independence. The aim of this study is to evaluate and compare the environmental impact of different wood pellet supply chains. A comparative cradle-to-grave life cycle assessment is performed considering the following wood feedstock systems: (i) sawdust from sawmill (S1), (ii) roundwood logs (S2), (iii) whole trees from forest thinning operation (S3), and (iv) logging residues produced during forest tree harvesting (S4). The study focuses on Global Warming Potential (GWP), Ozone Depletion Potential (ODP), Photochemical Ozone Creation Potential (POCP), and Human Toxicity Potential (HTP). Results show that $\mathrm{S} 3$ displays the lowest figures on all the environmental impact categories considered in this study. Compared to the reference case S1, S3 shows a GWP reduction of $46 \%$, an ODP reduction of $6.6 \%$, a POCP reduction of $14.8 \%$, and HTP reduction of $13.2 \%$. S3 and S4 have lower GWP than S1 and $\mathrm{S} 2$, even when the biogenic $\mathrm{CO}_{2}$ emissions are considered. Overall, the life cycle phases that have the highest GWP, POCP, and HTP are the burning phase and the preparation of the material to be pelletized, particularly the drying process. Nevertheless, the main phases that contribute to the ODP are the forest operations and the pellet preparation.
\end{abstract}

Keywords: biomass sources; wood pellets; bioenergy; forest wood feedstock; life cycle assessment; emissions; environmental impacts

\section{Introduction}

At the EU level, the bioenergy sector plays a driving role in achieving the new ambitious energy and climate goals for 2030, which impose a reduction of greenhouse gas (GHG) emissions of at least 40\% [1] and a renewable energy target of at least $32 \%$ of the total energy consumption [2]. Currently, bioenergy represents $64 \%$ of the total renewable energy resources, with the current consumption standing at $5.6 \mathrm{EJyr}^{-1}$ [3]. According to the Renewable Energy Directive (RED), $42 \%$ of the total renewable energy is expected to be obtained from biomass, including electricity, heating, and cooling [4].

Among different types of biomass, wood represents the main source, accounting for more than $60 \%$ of the whole EU domestic biomass supplied for energy purposes, providing an equivalent of 
82Mtoe [5]. In the last decade, wood pellets have become an important energy carrier, reaching a global production of more than 55 million tonnes in 2018 [6]. Currently, the EU is one of the largest producers and consumers of wood pellets in the world. In the period 2013-2018, the production of pellets in the EU increased by almost $41 \%$, reaching 20.1 million tonnes in 2018 , equal to around $36 \%$ of the global production. In the same year, the EU was responsible for around $50 \%$ of the world's wood pellet consumption, with 27 million tonnes consumed especially for heat production [6]. The demand for wood pellets exceeds the domestic EU production, and this additional demand is met by importing pellets, especially from the United States [6].

The increasing interest in wood pellets may be due to their peculiar characteristics. Compared to other traditional wood fuels (such as firewood or woodchips), wood pellets present higher energy density and more stable characteristics [7]. Pelletization provides consistent quality, low moisture content, high energy content, and homogenous shape and size that facilitate the logistics of this biomass [8], which is often traded for long distances.

Pellet production in Europe relies on the so-called secondary feedstock, which includes sawmill residues and other residues from the wood industry, whereas primary feedstock, such as roundwood and forest operation residues, accounts only for around $12 \%[6,9]$. The need to find alternative solutions for supply sources has fostered investments in research in this field [10].

A number of studies are looking into pathways for the efficient collection and processing of this residual woody biomass into marketable forms of bio-energy products [11-14]. Alternative forest biomass sources for wood pellets include the removal of a portion of logging residues generated during the harvesting of timberlands for conventional forest products (harvest slash) and the removal of excess biomass from thinning operations. Using these alternative forest raw materials as pellet feedstocks could also help reduce the risks and losses from wildfires and improve forest health [15-17].

When considering new pathways for the sustainable collection, processing and use of residual woody biomass for pellet production, it is important to understand the environmental impacts along the life cycle, as compared to the traditional pellet supply chain. The life cycle assessment (LCA) methodology is internationally recognized as a valuable tool for the evaluation of the environmental burdens associated with bioenergy production, by identifying energy and materials used, as well as waste and emissions released into the environment $[18,19]$. The LCA approach is increasingly adopted by legislative documents, including the Renewable Energy Directive [4], and it is also required in several certification schemes (i.e., Environmental Product Declaration, Carbon Footprint, etc.).

Indeed, in the last few years, several LCA studies have focused on the evaluation of the environmental impacts of pellet manufacturing [12,20-27]. Other studies focused on the assessment of greenhouse gas emissions of pellet production [28-30]. One of the most remarkable results of all these studies is that significant reductions in GHG emissions are obtained when wood pellets are used to replace fossil fuels. Some authors have pointed out the effect of the cascading utilization of various wood resources, showing the environmental and economic advantages of extending the service life of wood resources [31].

Nonetheless, in all these studies, the feedstock used to produce pellets was either roundwood logs coming from silvicultural activities or wood residues from industries, mainly sawdust, shavings, and chips from sawmill operations. Only a few studies addressing the environmental impacts of wood pellets from other forest feedstocks were found in the literature. For example, Röder et al. [32] examined the combustion of wood pellets to generate electricity from both sawmill residues and forest residues. In particular, the forest residues considered in this study mainly included whole trees from thinning operations (80\%) and, in small part, residues, such as tops, branches, and bark (20\%). In a study conducted by Giuntoli et al. [14], logging residues from forest operations were converted into different wood fuels (woodchips and wood pellets) and used in different combustion technologies.

The same study underlined the importance of including biogenic carbon to correctly estimate the GHG emissions of a forest-based system [14]. The carbon neutrality concept, embraced by the current EU bioenergy policy, implies that the total amount of carbon dioxide adsorbed during the 
growing life of a plant is then re-emitted with combustion [18,33-38]. Nevertheless, several studies argue that the share of biogenic carbon involved along the whole life cycle of the biofuel should not be ignored and that a dynamic approach should be used to evaluate the global warming effects of carbon sequestration and biogenic emissions [14,39-44]. Moreover, the origin of woody biomass used in pellet manufacturing plays a fundamental role in its quality certification $[45,46]$. In fact, a certified high-quality biofuel guarantees low harmful emissions during its combustion and therefore a lower environmental impact.

In this context, more research is needed to establish the environmental consequences of upgrading these wood forest resources to help meet the increased demand of quality certified wood pellets and foster local silvicultural and wood economies. The aim of the present work was to evaluate the environmental profile of different pellet supply chains, from raw material acquisition to final energy production, from a cradle-to-grave perspective, performing a LCA analysis. Four different pellet supply chains were considered, based on different raw materials: roundwood logs, whole trees after forest thinning operations, logging residues, and sawdust and wood residues from the lumber processing industry.

\section{Materials and Methods}

The scope of this study was the assessment and comparison of the environmental performance of four alternative supply chains for pellet production, described in detail in the following Section 2.1, using the LCA methodology. The LCA was performed according to the ISO 14040 and ISO 14044 standards $[47,48]$. As shown in Figure 1, the system boundary considered for the purpose of this investigation started in the forest, with the tree felling, and ended up at the energy production plant, in a cradle-to-grave perspective. The functional unit was $1 \mathrm{MJ}$ of thermal energy produced by burning wood pellets delivered to the final user.

The GaBi software was used to model the systems and to set up the environmental balances. $\mathrm{GaBi}$ is developed by Sphera Solution $\mathrm{GmbH}$ and it is one of the most used LCA modeling programs [49]. The software contains the most updated industry data and other commercial databases and regional content such as Ecoinvent and U.S. LCI. The environmental impacts of the pellet supply chains were calculated using the CML 2001-Apr. 2013 method, developed by the Institute of Environmental Sciences (CML) of Leiden University (The Netherlands) [50]. CML 2001 is an impact assessment method which restricts quantitative modeling to early stages in the cause-effect chain, grouping results into midpoint categories.

This study focused on key environmental impact categories in bioenergy LCA, namely local and global air pollution and impact on human health. Four impact categories were considered: Global Warming Potential (GWP), Ozone Depletion Potential (ODP), Photochemical Ozone Creation Potential (POCP), and Human Toxicity Potential (HTP). GWP, expressed in terms of carbon dioxide equivalents $\left(\mathrm{CO}_{2 \mathrm{eq}}\right)$, is the impact on global warming evaluated over a 100-year timeframe. $\mathrm{ODP}$, expressed in terms of trichlorofluoromethane equivalents $\left(\mathrm{R} 11_{\mathrm{eq}}\right)$, is the reduction of the ozone layer protection from UV radiation. Since there is no correlation between GWP, ODP, and the specific location where the emissions are generated, they are considered to have an impact at a global level. On the other hand, POCP, expressed in terms of ethylene equivalents (Ethene eq), and HTP, expressed in terms of dichlorobenzene equivalents $\left(\mathrm{DCB}_{\text {eq }}\right)$, are considered to have an impact at a local level, since their direct effects are strongly related to the place where they are emitted. Photochemical smog is created on days characterized by weather conditions of stability and strong sunlight. Nitrogen oxides and volatile organic compounds (VOCs) together, emitted in many natural processes, undergo a complex system of photochemical reactions induced by UV light from the sun that leads to the formation of ozone, perossiacetil nitrate (PAN), perossibenzoil nitrate (PBN), and hundreds of other substances. HTP is defined in LCA by four main groups of pollutants: heavy metals, inorganic emissions, VOCs, and particulate matter. Regarding the particulate matter, its degree of penetration into the human respiratory system and its consequent toxicity depends on the particle size distribution. It may be a 
vehicle of chemical agents, toxic to humans, such as heavy metals, polycyclic aromatic hydrocarbons, polychlorinated biphenyls, and dioxins generated by burning.

\subsection{System Description and Data Collection}

As shown in Figure 1, four different pellet supply chains were compared in the assessment. System 1 (S1) uses sawmill residues (sawdust, shavings, trims, and bark) as raw material to produce pellets, while system 2 (S2) uses roundwood logs. These two systems are the most common pellet supply chains in Europe. Another two options were investigated: system 3 (S3), which uses the standing softwood tree components (stem, branches, and needles) after thinning operations, and system 4 (S4), which is based on the use of logging residues.

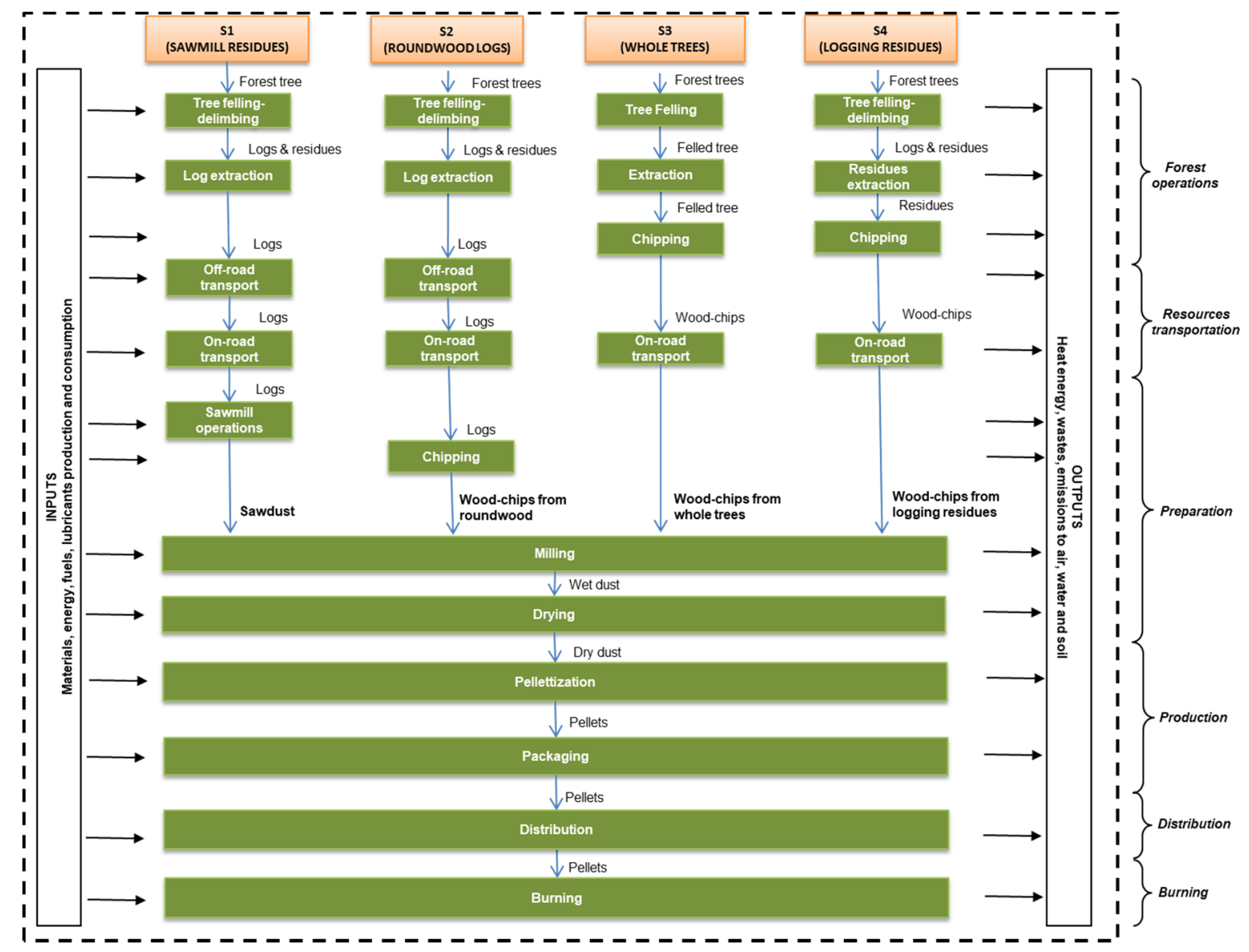

Figure 1. Process flow diagram of the investigated wood pellet supply chains. The dotted line shows the system boundary. Macro-phases are listed on the right of the figure.

In all four cases, the system boundary started with the felling of softwood trees, mainly Norway spruce (Picea abies L.). The forest operations were fully mechanized. The felling and delimbing of the trees were carried out using a medium-size harvester. In S3, the delimbing was not performed. The felled trees were moved to the forest road by means of a forwarder with a load capacity of 10-14 $t$, for an average distance of $300 \mathrm{~m}$, and then transported by truck (load capacity of $17.4 \mathrm{t}$ for S1 and S2, and load capacity of $25 \mathrm{t}$ for S3 and S4) to different locations, according to their end use. In S1, logs were transported to the sawmill, whereas in S2, logs were transported directly to the pellet plant site. In S3 and S4, whole trees and residues, respectively, were chipped directly at the roadside before being transported to the pellet plant. The on-road transportation distance was set to $50 \mathrm{~km}$ in all the scenarios. 
In S1, logs were debarked and sawn to obtain lumber. The by-products of lumber production, such as sawdust, shavings, and cutouts, were the pellet feedstock considered in this system. It has been assumed that the sawmill was equipped with a pelletizing plant. In S2, logs were debarked and chipped before undergoing pelletization. In order to be pelletized, the feedstock needed to be properly prepared. The feedstock was milled with a $350 \mathrm{MW}$ hammer mill, dried, and conditioned. As stated by the producers, corn starch was added in the S1 supply chain. For the drying process, a $1 \mathrm{MW}$ furnace fed with softwood woodchips was used. The dusty feedstock was pelletized with a $750 \mathrm{~kW}$ pellet press with a nominal productivity of $10 \mathrm{t} \mathrm{h}^{-1}$. After pelletization, wood pellets needed to be cooled down and sieved to remove possible dust. The ventilation, conveying system, and internal transportation within the pellet plant were also modeled. Pellets were then packed in $15 \mathrm{~kg}$ low density polyethylene (LDPE) plastic bags and transported to the consumer with a Euro 5 truck with a load capacity of 16-32 $t$, for an average distance of $300 \mathrm{~km}$. The final step consisted of burning pellets in a $50 \mathrm{~kW}$ automatic domestic boiler.

The life cycle inventory (LCI) phase involved the data collection for each process considered in the study. Primary data were collected by surveying EU pellet manufacturers and companies operating in the forestry sector. The selected pellet manufacturers were companies with an annual production between 38,000 and 90,000 t, which is the typical EU pellet production for companies equipped with one or more pellet presses with a nominal output of $10 \mathrm{th}^{-1}$. Data collected included quantity of feedstock, type of machinery, fuel, electricity, and others. Table 1 includes the main characteristics of the machines and equipment used in each scenario, while in the Supplementary Materials (Table S1), the main input and output data for each system are reported.

Table 1. Characterization of the machines and equipment involved in each scenario, as well as the main characteristics of the pellets produced from different wood feedstocks (S1: pellets produced from sawmill sawdust; S2: pellets produced from roundwood logs; S3: pellets produced from whole trees; S4: pellets produced from logging residues).

\begin{tabular}{|c|c|c|c|c|c|}
\hline & \multirow[b]{2}{*}{ Unit } & S1 & S2 & S3 & S4 \\
\hline & & Sawdust & Roundwood & $\begin{array}{l}\text { Whole } \\
\text { Trees }\end{array}$ & $\begin{array}{l}\text { Logging } \\
\text { Residues }\end{array}$ \\
\hline \multicolumn{6}{|c|}{ Operation and machine characteristics } \\
\hline Harvester & kW & 190 & 190 & 150 & 190 \\
\hline Forwarder & $\mathrm{kW}$ & 180 & 180 & 180 & 180 \\
\hline Chipper & $\mathrm{kW}$ & - & 132 & 335 & 335 \\
\hline Sawmill & $\mathrm{kWh} \mathrm{t}^{-1}$ & 90.5 & - & - & - \\
\hline Hammer mill & $\mathrm{kW}$ & 350 & 350 & 350 & 350 \\
\hline Dryer heat & $\mathrm{kWh} \mathrm{t}^{-1}$ & 896 & 896 & 727 & 1097 \\
\hline Conditioner & $\mathrm{kW}$ & 30 & 30 & 30 & 30 \\
\hline Press & $\mathrm{kW}$ & 750 & 750 & 750 & 750 \\
\hline $\begin{array}{l}\text { Nominal press } \\
\text { productivity }\end{array}$ & $\mathrm{th}^{-1}$ & 10 & 10 & 10 & 10 \\
\hline Real plant productivity & $\mathrm{th}^{-1}$ & 8 & 4.5 & 10 & 8 \\
\hline Cooler & $\mathrm{kW}$ & 50 & 50 & 50 & 50 \\
\hline Sieve & $\mathrm{kW}$ & 81 & 81 & 81 & 81 \\
\hline Internal transportation & $\mathrm{kW}$ & $220 \times 2$ & $220 \times 3$ & $220 \times 2$ & $220 \times 2$ \\
\hline $\begin{array}{l}\text { Ventilation and conveying } \\
\text { system }\end{array}$ & $\mathrm{kW}$ & 100 & 100 & 100 & 100 \\
\hline Packaging & $\mathrm{kW}$ & 90 & 90 & 90 & 90 \\
\hline Boiler & $\mathrm{kW}$ & 50 & 50 & 50 & 50 \\
\hline \multicolumn{6}{|l|}{ Pellet characteristics } \\
\hline Moisture content & $\%$ & 8 & 8 & 8 & 8 \\
\hline Net calorific value & $\mathrm{MJ} \mathrm{kg}^{-1}$ & 16.74 & 16.56 & 17.28 & 17.64 \\
\hline
\end{tabular}


Secondary data were retrieved from the literature and the Ecoinvent database [51], especially for the background processes (e.g., diesel, lubricant oil, electricity production, truck transports, etc.) and the emission factors. The life cycle inventory took into account the resources, the production emissions, and the consumption of fuel, lubricating oil, and electricity in each process. Machinery, infrastructure construction, and maintenance were outside the system boundary.

The four pellet supply chains generated both main products and residues, along the whole life cycle. Sawdust was a processing residue of lumber production in sawmills. Felling and logging operations also generated logging residues besides logs. When residues are included in an LCA model, practitioners are required to make choices on how to interpret them (if co-product or by-product) and, eventually, on how to allocate emissions among the different products generated along the bioenergy supply chain [52]. In this study, mass allocation on a dry basis was chosen, and the allocation factors used are reported in Table 2. The bark to log ratio was assumed to be roughly $10 \%$ based on Milota et al. [53].

Table 2. Mass allocation factors used in the four wood pellet supply chains assessed (S1: pellets produced from sawmill sawdust; S2: pellets produced from roundwood logs; S3: pellets produced from whole trees; S4: pellets produced from logging residues).

\begin{tabular}{cccccc}
\hline \multirow{2}{*}{ System Phases } & Supply Chain Products & \multicolumn{4}{c}{ Mass Allocation Factors (\%) } \\
& & S1 & S2 & S3 & S4 \\
\hline \multirow{2}{*}{ Felling and delimbing Assessed } & Logs & 67.5 & 67.5 & - & 67.5 \\
& Residues & 32.5 & 32.5 & - & 32.5 \\
& Whole trees & - & - & 100 & - \\
\hline \multirow{2}{*}{ Debarking } & Debarked logs & 90 & 90 & - & - \\
& Bark & 10 & 10 & - & - \\
\hline \multirow{2}{*}{ Sawing } & Lumber & 50 & - & - & - \\
& Sawmill by-products & 50 & - & - & - \\
\hline
\end{tabular}

\section{Results}

Figure 2 shows the comparison of the total impacts for the four scenarios and for the four impact categories analyzed. The results are provided in percentages, relative to the system S1, which also serves as the reference scenario (set to 100\%). As shown in Figure 2, among all scenarios, S3 has the lowest environmental impact for all the impact categories considered. Compared to the scenario S1, excluding biogenic $\mathrm{CO}_{2}$ emissions, $\mathrm{S} 3$ shows a GWP reduction of $46 \%$, an ODP reduction of $6.6 \%$, a POCP reduction of $14.8 \%$, and an HTP reduction of $13.2 \%$. If biogenic $\mathrm{CO}_{2}$ emissions are included in the GWP calculation, S3 shows a GWP reduction of around 15\% compared to S1. 


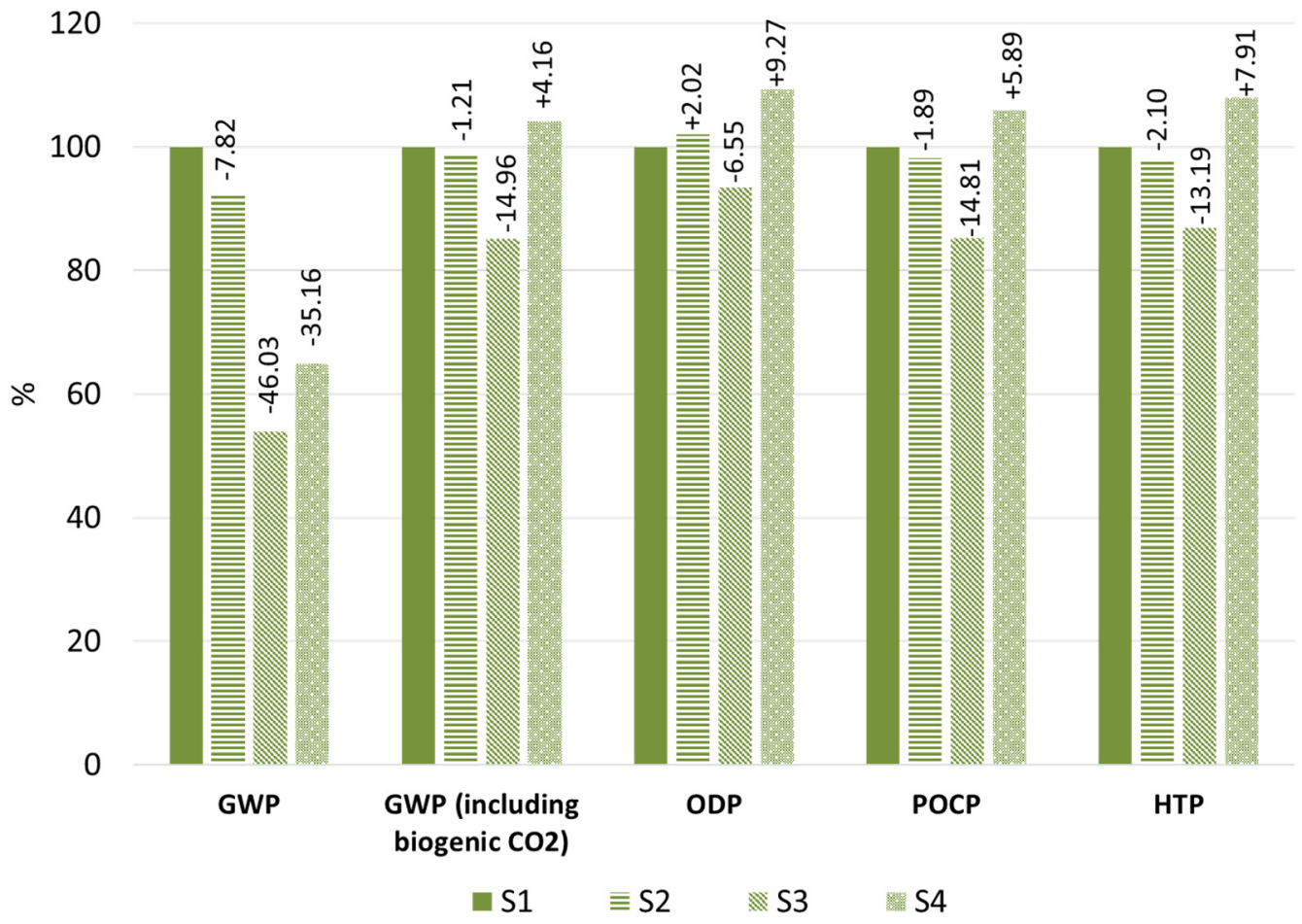

Figure 2. Comparison of the four pellet production systems assessed (S1: pellets produced from sawmill sawdust; S2: pellets produced from roundwood logs; S3: pellets produced from whole trees; S4: pellets produced from logging residues) in terms of Global Warming Potential excluding biogenic $\mathrm{CO}_{2}(\mathrm{GWP})$, Global Warming Potential including biogenic $\mathrm{CO}_{2}$ (GWP including biogenic $\mathrm{CO}_{2}$ ), Ozone Depletion Potential (ODP), Photochemical Ozone Creation Potential (POCP), and Human Toxicity Potential (HTP).

In the following paragraphs, the results of the contribution analysis are presented for each impact category. The processes involved in each system are grouped into six macro-phases, specifically designed for the scope of the study, namely (i) forest operations, (ii) transportation of the resources, (iii) preparation, (iv) production, (v) transportation of the final product, and (vi) burning. These macro-phases are described in detail in Section 2 and are displayed in Figure 1. Figure 3 shows the contributions of the six macro-phases to the impact categories. The list of chemicals emitted for the considered impact categories is reported in Table 3. Results are given per functional unit.

\subsection{Global Warming Potential (GWP)}

According to the carbon neutrality assumption, in the case of sustainable forest management, the $\mathrm{CO}_{2}$ emissions released by combustion or decomposition of biomass (biogenic $\mathrm{CO}_{2}$ ) are offset by the $\mathrm{CO}_{2}$ adsorbed by the forest through photosynthesis. Based on this assumption, in traditional LCA, biogenic $\mathrm{CO}_{2}$ emissions are not included in the evaluation of the GWP. Given the importance of this contribution in the LCA of bioenergy systems, in this study, the contribution of biogenic $\mathrm{CO}_{2}$ emissions is evaluated and reported separately.

Excluding biogenic $\mathrm{CO}_{2}$ emissions, the scenario with the lowest GWP is $\mathrm{S} 3$ with $14.9 \mathrm{gCO}_{2 \mathrm{eq}}$ followed by S4 with $17.9 \mathrm{~g} \mathrm{CO}_{2 \text { eq }}$, S2 with $25.4 \mathrm{~g} \mathrm{CO}_{2 \text { eq, }}$ and $\mathrm{S} 1$ with $27.6 \mathrm{~g} \mathrm{CO}_{2 \text { eq. }}$. In general, the main contribution to GWP occurs during the preparation stage, which accounts for $47 \%$ in $51,40 \%$ in $\mathrm{S} 4,33 \%$ in $\mathrm{S} 3$, and $32 \%$ in $\mathrm{S} 2$. This is mainly due to $\mathrm{CO}_{2}$ and $\mathrm{N}_{2} \mathrm{O}$ emissions during the drying and milling processes. In $\mathrm{S} 1$, the sawmill operations, which have large electricity and diesel inputs, represent the most impacting phase of the whole supply chain. Indeed, the sawmill processes are responsible for $46 \%$ of the GWP generated within the preparation phase and for the $22 \%$ of the GWP produced within the whole life cycle. The production phase shows the second most important contribution to GWP, with figures ranging from $4.5 \mathrm{~g} \mathrm{CO}_{2 \text { eq }}$ in $\mathrm{S} 3$ to $7.9 \mathrm{~g} \mathrm{CO}_{2 \mathrm{eq}}$ in S2. The pelletizing 
process, whichis included in the production phase, accounts for the majority (from 51\% in S3 to 64\% in S2) of the emissions.

Forest operations show higher emission levels in $\mathrm{S} 1$ and $\mathrm{S} 2$ than in the other two scenarios. This is mainly due to the biogenic methane $\left(\mathrm{CH}_{4}\right)$ released in the forest during the decomposition of the residues left on the felling site. The transportation of pellets to the final user, set to $300 \mathrm{~km}$, represents a moderate GWP emission source that is kept constant for all scenarios, accounting for $3.3 \mathrm{~g} \mathrm{CO}_{2 \mathrm{eq}}$.

As far as the burning phase is concerned, the emissions that contribute to GWP, excluding biogenic $\mathrm{CO}_{2}$, are within the same range for all the supply chains assessed. Some small differences depend on the different calorific value of the feedstock used, which affects the net calorific value of the pellets (the pellets' moisture content is assumed to be constant at $8 \%$ ).

Including biogenic $\mathrm{CO}_{2}$ emissions, the GWP figures per functional unit rise to $159.8 \mathrm{~g} \mathrm{CO}_{2 \mathrm{eq}}$ in $\mathrm{S} 3,185.7 \mathrm{~g} \mathrm{CO}_{2 \mathrm{eq}}$ in $\mathrm{S} 2,188 \mathrm{~g} \mathrm{CO}_{2 \mathrm{eq}}$ in $\mathrm{S} 1$, and $196 \mathrm{~g} \mathrm{CO}_{2 \mathrm{eq}}$ in $\mathrm{S} 4$. The differences in biogenic $\mathrm{CO}_{2}$ emissions among the four scenarios are mainly due to (i) the different calorific values of the four types of materials involved in the burning phase; (ii) the different levels of moisture content of the feedstock before the drying phase, which influences the quantity of biomass needed for drying; (iii) the different processes added to the preparation phase in S1.

\subsection{Ozone Depletion Potential (ODP)}

The production of $1 \mathrm{MJ}$ of energy from pellets in domestic heating through the whole life cycle is responsible for the emission of $1.85 \mu \mathrm{g} \mathrm{R} 11_{\mathrm{eq}}$ in S3, $1.98 \mu \mathrm{g} \mathrm{R} 11_{\mathrm{eq}}$ in S1, $2.02 \mu \mathrm{g} \mathrm{R} 11_{\mathrm{eq}}$ in S2, and $2.16 \mu \mathrm{g}$ $\mathrm{R} 11_{\mathrm{eq}}$ in S4. Results show that $100 \%$ of the ODP is due to organic emission to air (group VOC-volatile organic compounds). It may be noted that these chemicals are produced in very small quantities, of the order of a few micrograms.

The specific emission potential of each life cycle phase of the supply chain varies based on the efficiency of the equipment used. For example, the high emissions of the forest operations in S3 and S4 are related to the low productivity of the harvesting and forwarding operations, as well as the chipping operation at the roadside, which is performed by means of diesel engine powered chippers.

In $\mathrm{S} 1$, the preparation phase is responsible for the highest share of ODP, accounting for $30 \%$ of the impact. In particular, the sawing activities are the major contributors to this phase, accounting for $45 \%$. In the other supply chains, the drying process is the most important contributor within the pellet preparation phase: $62 \%$ in S3, 66\% in S2, and 70\% in S4.

The emissions of the production phase depend on the specific press productivity and secondarily on the internal transportation stage. It should be noted that in S2, this phase is the most important, covering $30 \%$ of the total ODP. Furthermore, pellet distribution contributes substantially to the overall ODP, accounting for $0.52 \mu \mathrm{g}$ R11 $\mathrm{eq}$.

\subsection{Photochemical Ozone Creation Potential (POCP)}

The overall life cycle POCP accounts for $19.8 \mathrm{mg}$ Ethene $_{\text {eq }}$ in S1, to $19.5 \mathrm{mg}$ Ethene $_{\text {eq }}$ in S2, $16.9 \mathrm{mg}$ Ethene $_{\mathrm{eq}}$ in S3, and $21.0 \mathrm{mg}$ Ethene $_{\mathrm{eq}}$ in S4. Combustion is widely recognized to play a crucial role in terms of pollutant formation $[54,55]$. The main variables that affect the combustion emissions are the combustion efficiency and the pollutant removal efficiency. All these variables are affected by the fuel type and its composition [54].

Results show that the potential impact on POCP is considerably higher in the life cycle phases where combustion is present (i.e., preparation and burning). The burning and the preparation phases, when considered together, cause more than $60 \%$ of the whole POCP, in all the supply chains assessed. The POCP from the burning phase accounts for $6 \mathrm{mg}$ Ethene $\mathrm{eq}_{\text {in }}$ all the analyzed systems. The emissions occurring within the preparation phase are dominated by the drying process, contributing to at least $70 \%$. The POCP of S4 (8.4 mg Ethene $e_{\text {eq, }}$ including conditioning, drying, and milling) is higher than S1

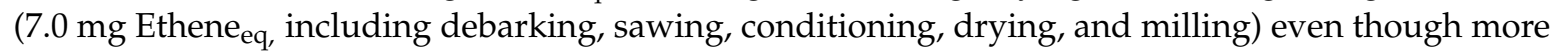
processes are involved in the latter. 
Looking at the individual pollutants causing the $\mathrm{POCP}, \mathrm{NO}_{2}$ is the main contributor among the non-organic emissions, followed by biogenic $\mathrm{CO}$ and $\mathrm{SO}_{2}$. Among the organic emissions, the main contributors are the non-methane volatile organic compounds (NMVOCs), followed by the biogenic $\mathrm{CH}_{4}$.

\subsection{Human Toxicity Potential (HTP)}

Similarly to the POCP, HTP is also mainly caused by biomass combustion emissions, so the main contributions to HTP are related to the drying and burning phases. In all the scenarios, the share of HTP due to the burning process is greater than $40 \%$ (maximum value $59.6 \%$ for S3) and the share of HTP due to the drying process is greater than $24 \%$ (maximum value $40.8 \%$ for S4). These two processes alone cover at least $83 \%$ of the total HTP.

The four groups of pollutants contributing to HTP are, in descending order, organic emissions, heavy metals, inorganic emissions, and particles/dust. The same groups of pollutants have been reported in other studies on firewood [56]. Organic emissions produced by combustion include polycyclic aromatic hydrocarbons (PAH), halogenated organic emissions, polychlorinated dibenzo-p-dioxins (2,3,7,8-TCDD), benzene, and formaldehyde. Heavy metals contained in wood are also released into the atmosphere during burning. Heavy metals posing the greatest human health hazard are Arsenic (+V), Nickel (+II), Chromium (+VI), Cadmium (+II), Lead (+II) (Table 3). Inorganic emissions, already contributing to other impact categories, such as GWP and POCP, have also a direct impact on human health. These include nitrogen oxides, hydrogen fluoride, hydrogen chloride, and ammonia. Combustion is responsible for the production of particulate matter, with fine and ultrafine particulate matter $\left(\mathrm{PM}_{2.5}\right)$ being the most harmful.
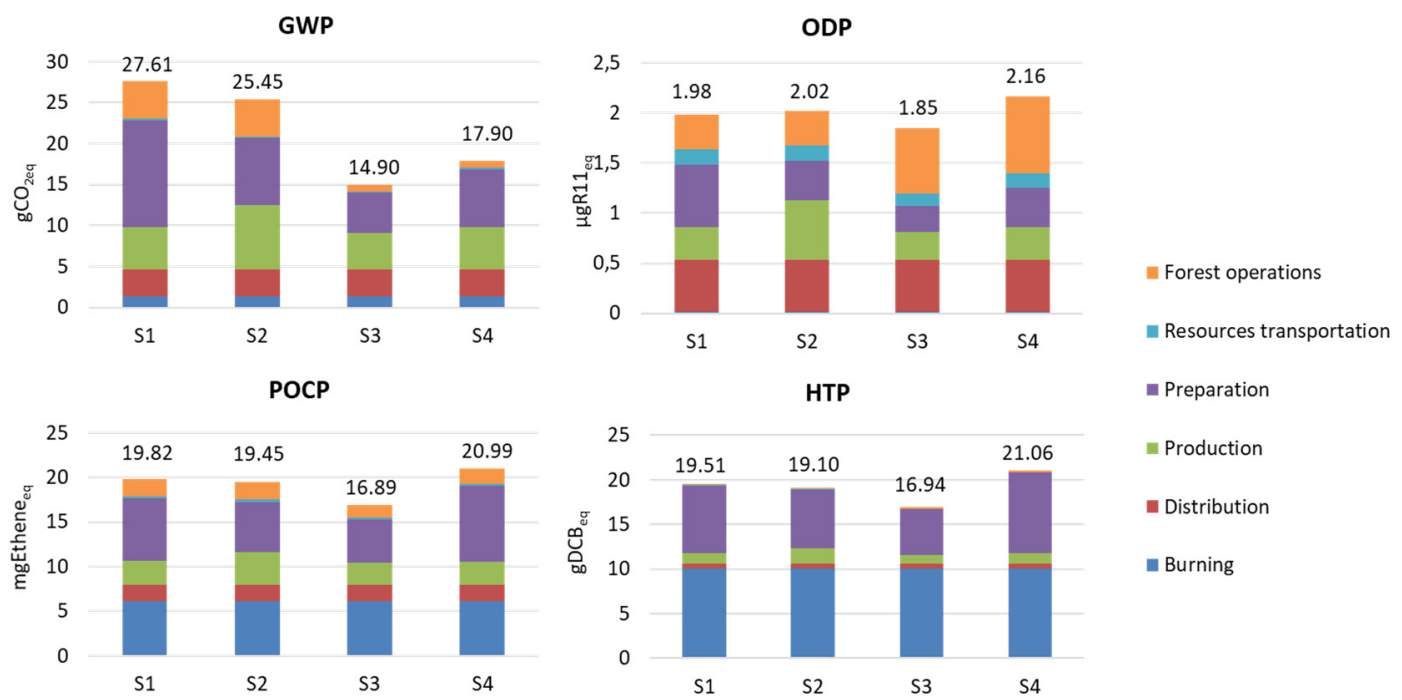

Figure 3. Specific environmental impacts for all four pellet supply chains (S1: pellets from sawmill sawdust; S2: pellets from roundwood; S3: pellets from whole trees, S4: pellets from logging residues) grouped per impact category (GWP: Global Warming Potential, ODP: Ozone Depletion Potential, POCP: Photochemical Ozone Creation Potential and HTP: Human Toxicity Potential). 
Table 3. Specific emission quantities grouped per impact category (GWP: Global Warming Potential, ODP: Ozone Depletion Potential, POCP: Photochemical Ozone Creation Potential and HTP: Human Toxicity Potential) and systems assessed (S1: pellets from sawmill sawdust; S2: pellets from roundwood; S3: pellets from whole trees, S4: pellets from logging residues) for the production of $1 \mathrm{MJ}$ of thermal energy by burning wood pellets delivered to the final user.

\begin{tabular}{|c|c|c|c|c|}
\hline Emissions & $\begin{array}{c}\text { S1 } \\
\text { Sawdust }\end{array}$ & $\begin{array}{c}\text { S2 } \\
\text { Roundwood }\end{array}$ & $\begin{array}{c}\text { S3 } \\
\text { Whole Trees }\end{array}$ & $\begin{array}{c}\text { S4 } \\
\text { Logging } \\
\text { Residues }\end{array}$ \\
\hline GWP & \multicolumn{4}{|c|}{$\mathrm{g} \mathrm{CO}_{2 \mathrm{eq}}$} \\
\hline Emissions to air (total) & 187.97 & 185.70 & 159.84 & 195.79 \\
\hline Carbon dioxide (biotic) & 160.36 & 160.25 & 144.94 & 177.89 \\
\hline Carbon dioxide & 20.97 & 18.92 & 12.97 & 15.58 \\
\hline Nitrous oxide & 1.33 & 1.31 & 1.18 & 1.42 \\
\hline Methane (biotic) & 4.24 & 4.24 & 0.04 & 0.05 \\
\hline Methane & 1.03 & 0.95 & 0.68 & 0.80 \\
\hline Group NMVOC to air ${ }^{a}$ & 0.03 & 0.03 & 0.03 & 0.05 \\
\hline ODP & \multicolumn{4}{|c|}{$\mu \mathrm{g} \mathrm{R} 11_{\mathrm{eq}}$} \\
\hline Halogenated organic emissions to air ${ }^{b}$ & 1.98 & 2.02 & 1.85 & 2.16 \\
\hline POCP & \multicolumn{4}{|c|}{ mg Ethene $e_{\mathrm{eq}}$} \\
\hline Emissions to air (total) & 19.82 & 19.45 & 16.88 & 20.98 \\
\hline Carbon monoxide (biotic) & 2.49 & 2.49 & 2.34 & 2.70 \\
\hline Group NMVOC to air & 7.41 & 7.44 & 7.53 & 9.44 \\
\hline Nitrogen oxides & 4.98 & 4.89 & 4.29 & 5.40 \\
\hline Carbon monoxide & 0.50 & 0.49 & 0.56 & 0.80 \\
\hline Sulfur dioxide & 3.16 & 2.89 & 1.99 & 2.45 \\
\hline Methane (biotic) & 1.02 & 1.02 & 0.01 & 0.01 \\
\hline Methane & 0.25 & 0.23 & 0.16 & 0.19 \\
\hline HTP & \multicolumn{4}{|c|}{$\mathrm{g} \mathrm{DCB}_{\mathrm{eq}}$} \\
\hline Heavy metals to air ${ }^{c}$ & 3.96 & 3.72 & 2.97 & 3.71 \\
\hline Inorganic emissions to air ${ }^{d}$ & 0.92 & 0.83 & 0.53 & 0.67 \\
\hline $\begin{array}{l}\text { Organic emissions to air (group } \\
\text { VOC-volatile organic compound) }\end{array}$ & 14.54 & 14.46 & 13.36 & 16.57 \\
\hline Polycyclic aromatic hydrocarbons (PAH) & 11.30 & 11.30 & 10.50 & 13.10 \\
\hline Other organic emissions to air $\mathrm{e}^{\mathrm{a}}$ & 3.13 & 3.05 & 2.76 & 3.35 \\
\hline Halogenated organic emissions to air ${ }^{f}$ & 0.11 & 0.11 & 0.10 & 0.13 \\
\hline Particles & $1.01 \times 10^{-1}$ & $9.89 \times 10^{-2}$ & $8.39 \times 10^{-2}$ & $1.11 \times 10^{-1}$ \\
\hline Dust (PM2.5) & $4.83 \times 10^{-2}$ & $4.79 \times 10^{-2}$ & $3.99 \times 10^{-2}$ & $5.69 \times 10^{-2}$ \\
\hline Dust (>PM10) & $5.07 \times 10^{-2}$ & $4.95 \times 10^{-2}$ & $4.27 \times 10^{-2}$ & $5.22 \times 10^{-2}$ \\
\hline Dust (PM2.5-PM10) & $1.60 \times 10^{-3}$ & $1.50 \times 10^{-3}$ & $1.31 \times 10^{-3}$ & $1.60 \times 10^{-3}$ \\
\hline Silicon dust & $4.65 \times 10^{-5}$ & $4.10 \times 10^{-5}$ & $2.61 \times 10^{-5}$ & $3.35 \times 10^{-5}$ \\
\hline
\end{tabular}

a NMVOC (Non-Methane Volatile Organic Compounds): 1,1,1-Trichloroethane, Chloromethane (methyl chloride), Dichloromethane (methylene chloride), Tetrachloroethene (perchloroethylene), Trichloromethane (chloroform), Vinyl chloride (VCM; chloroethene), 1-Butanol, 1-Pentene, 2-Methyl-2-butene, Acetaldehyde (Ethanal), Acetic acid, Acetone (dimethylcetone), Alkane (unspecified), Benzaldehyde, Benzene, Butadiene, Butane, Butanone (methyl ethyl ketone), Cumene (isopropylbenzene), Ethane, Ethanol, Ethene (ethylene), Ethine (acetylene), Ethyl benzene, Ethylene acetate (ethyl acetate), Formaldehyde (methanal), Formic acid (methane acid), Heptane (isomers), Hexane (isomers), iso-Butanol, Isoprene, Isopropanol, Methanol, Methyl acetate, Methyl formate, Methyl tert-butylether, NMVOC (unspecified), Pentane (n-pentane), Propane, Propene (propylene), Propionaldehyde, Propionic acid (propane acid), Styrene, Toluene (methyl benzene), Xylene (dimethyl benzene), Xylene (meta-Xylene; 1,3-Dimethylbenzene). ${ }^{\mathrm{b}}$ Halon (1301), Halon (1211), R 22 (chlorodifluoromethane), R 114 (dichlorotetrafluoroethane), Carbon tetrachloride (tetrachloromethane), R 12 (dichlorodifluoromethane), R 113 (trichlorotrifluoroethane), Chloromethane (methyl chloride), R 11 (trichlorofluoromethane), 1,1,1-Trichloroethane. ${ }^{c}$ Arsenic (+V), Nickel (+II), Chromium (+VI), Cadmium (+II), Copper (+II), Zinc (+II), Vanadium (+III), Lead (+II), Chromium (unspecified), Selenium, Mercury $(+\mathrm{II})$, Cobalt, Antimony, Molybdenum, Thallium, Tin (+IV), Hydrogen arsenic (arsine). ${ }^{\mathrm{d}}$ Nitrogen oxides, Hydrogen fluoride, Sulfur dioxide, Ammonia, Beryllium, Barium, Carbon disulfide, Hydrogen chloride, Hydrogen sulfide. e Benzene, NMVOC (unspecified), Formaldehyde (methanal), Toluene (methyl benzene), Propylene oxide, Ethyl benzene, Ethylene oxide, Xylene (meta-Xylene; 1,3-Dimethylbenzene), Ethene (ethylene), Xylene (dimethyl benzene), Butadiene, Acrolein, Phenol (hydroxy benzene), Styrene. ${ }^{\mathrm{f}}$ Polychlorinated dibenzo-p-dioxins (2,3,7,8-TCDD), Hexachlorobenzene (Perchlorobenzene), Vinyl chloride (VCM; chloroethene), Dichloroethane (ethylene dichloride), Carbon tetrachloride (tetrachloromethane), Pentachlorophenol (PCP), Trichloromethane (chloroform), Dichlorobenzene (o-DCB; 1,2-dichlorobenzene), 2,4-Dichlorophenol, Pentachlorobenzene, Dichloromethane (methylene chloride), 11,1-Trichloroethane, Tetrachloroethene (perchloroethylene), Methyl bromide. 


\section{Discussion}

Regarding GWP, the results of this study are consistent with other results found in the literature. For example, in Hansson et al. [57], the total GWP for wood pellet production at the conversion facility ranges between 2 and $25 \mathrm{~g} \mathrm{CO}_{2 \text { eq }}$ per MJ of pellet, with Swedish pellets at the lower end of the spectrum and Russian pellets, which use natural gas for drying the raw material, at the higher end [57]. Giuntoli et al. [14] calculated a GWP of $15 \mathrm{~g} \mathrm{CO}_{2 \mathrm{eq}} / \mathrm{MJ}_{\text {th }}$ for a pellet stove fed with forest residues, which is similar to the GWP figure when logging residues are used (S4). The results of this study are also in line with those reported by other authors [28,30,58] and are consistent with the default European GHG emission figures calculated at plant-gate level (i.e., excluding the biomass delivery to final users and its combustion) for specific bioenergy pathways, namely $18 \mathrm{~g} \mathrm{CO} \mathrm{C}_{2 \mathrm{eq}} / \mathrm{MJ}_{\text {th }}$ and $19 \mathrm{~g}$ $\mathrm{CO}_{2 \mathrm{eq}} / \mathrm{MJ}_{\mathrm{th}}$ for pellets derived from stem wood and from forest residues, respectively [59].

Quinteiro et al. [27] found a GWP of $7.8 \mathrm{~g} \mathrm{CO}_{2 \mathrm{eq}} / \mathrm{MJ}_{\mathrm{th}}$ for burning pellets from maritime pine logs in a $9.5 \mathrm{~kW}$ household pellet stove, which is three times lower than the GWP of S2. Pergola et al. [26] performed a comparative LCA of the production of 1 tonne of packed pellets derived from two different wood sources: sawmill residues and roundwood logs [26]. Surprisingly, they found that the supply chain based on sawmill residues emitted around half of the $\mathrm{CO}_{2 \text { eq }}$ generated by the supply chain based on roundwood logs [26]. This is in contrast with the results of this study, where the supply chain based on roundwood logs (S2) seems to perform better than the one using sawdust as pellet feedstock (S1). Nevertheless, in the above mentioned LCA studies, the preparation and the production phases (especially the pelletizing process) were the main contributors to GHG emission [14,25-27], as found in this study.

In general, these discrepancies in the results may be due to several reasons: distinct system boundaries (e.g., inclusion of machinery and building infrastructures), dissimilarity of biomass characteristics (i.e., heating value and moisture content), variation in machineries involved (e.g., type, efficiency, and consumption, etc.), and different assumptions made (e.g., forest management, type of energy used in the pelletizing plant, transport distances, product end-of-life, etc.).

As far as other environmental impacts are concerned, the results of other studies are often not comparable, due to several factors. Available LCAs usually focus on GWP and energy demands; different impact assessments methods are used, often implying different impact categories evaluated; and, sometimes, the results are reported as damage or are normalized, as occurred in Fantozzi and Buratti [21] and in Cespi et al. [54]. Nonetheless, some analogies may be drawn. Generally, ODP is mainly due to the final pellet combustion and thermal energy generation [27] when the system boundary ends up with the burning phase, or, when considering a cradle-to-gate LCA approach, the main contribution to ODP is the pellet production phase [25,26]. Moreover, there is a general consensus on the fact that the combustion of biomass is responsible for local scale impacts $[14,27,56]$, such as the photochemical ozone formation and human toxicity, as the results of this study further support. Actions to reduce these impacts may include promoting the correct use of more efficient and performing stoves together with the exploitation of certified high-quality biomass, derived from sustainably managed certified forests.

An important aspect of this LCA study that needs further discussion is the role of transportation in the overall global warming impact of wood pellet products. Some LCA studies have identified the transportation of wood pellets to the final user as a major source of greenhouse gas emissions. For example, Murphy et al. [29] evaluated the GHG emissions and the energy demand related to the production of several wood products, including pellets. The results revealed that transportation was the most energy and GHG emission intensive process, with $60 \%$ of the total GHG emissions in some pellet production scenarios [29]. Contrarily, in this research, even restricting the system boundaries to exclude the use phase (e.g., the burning), resource transportation together with pellet distribution play a minor role in the GWP, ranging from $13 \%$ in $\mathrm{S} 1$ to $25 \%$ in $\mathrm{S} 3$.

The contribution of wood pellet distribution to the total life cycle environmental impact is highly dependent on the transportation distance scenario; hence, the variations in the environmental impact 
of wood pellets are discussed assuming alternative transportation distances. With a wood pellet consumption that exceeds its production, wood pellets in the EU are typically produced for domestic use. Therefore, a domestic transportation scenario is considered, with transportation distances varying between 50 and $1500 \mathrm{~km}$. Within this range and across the four wood pellet supply chains S1-S4, the contribution of transportation to the total impact varies between $2.22 \%$ and $58.8 \%$ for GWP, $5.04 \%$ and $66.33 \%$ for ODP, $1.62 \%$ and $38.69 \%$ for POCP, and $0.37 \%$ and $12.14 \%$ for HTP. It may be noted that impact categories such as GWP, ODP, and POCP are more sensitive to variations in the transportation distance than HTP.

Beyond a certain transportation distance, the transportation phase becomes the main contributor to the life cycle environmental impacts. These "critical" transportation distances were evaluated for each impact category, and the highest distance across the four supply chains was selected. The results reveal a critical distance for GWP of $1185 \mathrm{~km}$, for ODP of $437 \mathrm{~km}$, for POCP of $1337 \mathrm{~km}$, and for HTP of $6645 \mathrm{~km}$. This analysis provides important insights into how to interpret the results of this study. For example, as the critical distance for HTP exceeds realistic transportation distances for the domestic distribution of pellets in the EU, we can conclude that the burning phase is the main contributor to HTP, independently of the transportation distance scenario. However, the results of the contribution analysis for GWP, ODP, and POCP are strictly dependent on the transportation distance, and this should be taken into consideration when comparing these results with other studies.

In the quality certification of solid biofuels (ISO 17225 standard series), the origin of biofuel is one of the mandatory parameters. As defined in the ISO 17225-2 [46], the best classes for pellet quality certification are A1 and A2 for domestic use and I1 and I2 for industrial use. Pellets belonging to property classes A1, A2, I1, and I2 are made from virgin wood and chemically untreated wood residues, the same type of the feedstock analyzed in this study. In particular, the origins stated by the standard for domestic use (the most restrictive) are steam wood, chemically untreated wood residues (A1 and $\mathrm{A} 2)$, whole trees without roots, and logging residues (A2). The A1 pellets represent solid biofuels which are low in ash $(\leq 0.7 \%)$ and nitrogen content $(\leq 0.3 \%)$, while class A2 has slightly higher ash $(\leq 1.2 \%)$ and nitrogen content $(\leq 0.5 \%)$ [46]. With the same domestic burning appliance, these characteristics are assessed to guarantee the lowest harmful emissions during combustion. The results obtained in this study are in line with what was reported in the standard, but, if all the production phases are considered, the S3 and S2 scenarios should be preferred in order to guarantee the lowest emissions during the entire pellet supply chain.

Though the quality of a solid biofuel is certainly a driving factor in the definition of its price, several other aspects may also influence it. Besides a possible higher cost of the raw material, additional costs for voluntary quality certification may increase the final price of the product [60]. Regarding the wood pellet supply chain costs, based on recent bibliographic research [61], the main costs across the entire supply chain are attributable to feedstock costs and pelletizing operating costs, including additional feedstock used for drying.

Finally, though this study did not explicitly compare the GWP of wood pellets with that of alternative fossil fuels, several studies have highlighted the global warming benefits of replacing fossil fuels with wood pellets [56]. Buchholz et al. [30] reported a net GHG emission reduction for residential heating in the US Northern Forest region of $64.4 \%, 62.2 \%$, and $49 \%$ when wood pellets substituted coal, heating oil, and natural gas, respectively. In a study conducted by Giuntoli et al. [14], the GHG savings obtained from the forest residue-based bioenergy systems ranged between $80 \%$ and $96 \%$ when compared to a reference natural gas system [14]. Despite the evident benefit for climate change, it has been shown that wood pellet domestic heating systems present higher values for other environmental impacts, such as photochemical ozone formation, particulate matter emission, acidification [14], and human toxicity [54], when compared to natural gas. The "best environmental option" does not seem to exist [27], since one option performs better for some environmental impacts but worse in others. However, LCA allows us to translate the different environmental impacts into a single unit, in order to obtain a result at an aggregated level $[47,48]$. In the study performed by Cespi 
et al. [54], where the most widespread alternative technologies for domestic heating available in the Italian market (such as wood stove, pellet stove, gas boiler, solar panel, and heat pumps) have been compared on a single score basis, pellet stoves presented the best performance.

\section{Conclusions}

With several wood resources available for wood pellet production, investigating the environmental consequences of upgrading this raw material using a holistic and LCA-based approach is critical. Comparing the environmental impacts of the four supply chains which were the object of study, the results of the LCA analysis show that the two systems that use whole trees from thinning operations (S3) and residues from forest operations (S4) have lower GWP than the supply chains that use sawmill residues (S1) and roundwood (S2) as feedstock. When biogenic $\mathrm{CO}_{2}$ emissions are included in the GWP evaluation, S4 results in the highest GWP. While the environmental impacts of S3 are lower than the reference scenario S1 for all the impact categories, the scenario S4 presents slightly higher impact on ODP, POCP, and HTP.

Along the whole pellets' life cycle, some processes represent hotspots or areas of concern. For GWP, these include the drying process during the preparation phase and the pelletizing process within the production phase. The wood pellet distribution phase is a main source of ODP, whereas the burning phase plays a major role in HTP. However, for all the impact categories except for HPT, the transportation of wood pellets to the final user becomes the main contributor to the life cycle environmental impacts beyond a certain transportation distance. This threshold distance is $1185 \mathrm{~km}$ for GWP, $437 \mathrm{~km}$ for ODP, and $1337 \mathrm{~km}$ for POCP.

This study shows that, from both an environmental and a quality perspective, the whole trees from thinning operations (S3) represent an excellent feedstock that could be used for the production of wood pellets. The whole tree system extraction allows us to avoid debarking and any sorting processes. This, coupled with high press productivity that is facilitated by the optimal mixture of wood and bark into the feedstock, allows us to produce very durable pellets. This type of feedstock may be used to meet the increasing demand for wood pellets in the EU, while simultaneously improving forest health and creating economic opportunities within the forest sector. Nevertheless, when using forest residues to produce wood pellets (S4), a trade off exists between global warming benefits and local pollution. These comparisons could be set as a starting point for the optimization of the environmental performance of different supply chains and for the identification of strategies to improve the efficiency of woody biomass-based bioenergy systems.

A possible future development of this research includes comparing the environmental impact of wood pellets from forest residues and imported wood pellets. Additionally, as social and economic aspects were not considered in this assessment, even though they are essential pillars of sustainability, a life cycle costing (LCC) and a social life cycle assessment (SLCA) may be carried out in order to provide a more complete picture of the sustainability of the different pellet supply chains.

Supplementary Materials: The following are available online at http://www.mdpi.com/1999-4907/11/11/1127/s1, Table S1: Inventory data of the four pellet production systems assessed (S1: pellets produced from sawmill sawdust; S2: pellets produced from roundwood logs; S3: pellets produced from whole trees; S4: pellets produced from logging residues).

Author Contributions: Conceptualization, A.S., F.P., M.B.; data curation, A.S., F.P.; formal analysis: A.S., F.P.; investigation, A.S., F.P.; methodology, F.P.; writing—original draft, A.S., M.B., F.P.; writing—review and editing, F.P., M.B., M.Z.; validation, F.P., M.B., M.Z.; visualization, M.B., F.P.; project administration, R.C., M.Z.; resources, R.C., M.Z.; supervision, R.C., M.Z. All authors have read and agreed to the published version of the manuscript.

Funding: This research received no external funding.

Acknowledgments: The authors kindly thank James A. Kuchenbecker (University of Washington, Seattle) for his valuable English language revision.

Conflicts of Interest: The authors declare no conflict of interest. 


\section{References}

1. European Commission 2030. Climate and Energy Framework. Available online: https://ec.europa.eu/clima/ policies/strategies/2030_en (accessed on 28 August 2020).

2. Directive (EU) 2018/2001 of the European Parliament and of the Council of 11 December 2018 on the Promotion of the Use of Energy from Renewable Sources (Text with EEA Relevance.). 2018. Available online: https://eur-lex.europa.eu/legal-content/EN/TXT/?uri=CELEX\%3A32018L2001 (accessed on 28 August 2020).

3. Mandley, S.J.; Daioglou, V.; Junginger, H.M.; van Vuuren, D.P.; Wicke, B. EU bioenergy development to 2050. Renew. Sustain. Energy Rev. 2020, 127. [CrossRef]

4. Directive 2009/28/EC of the European Parliament and of the Council of 23 April 2009 on the Promotion of the Use of Energy from Renewable Sorurces and Amending and Subsequently Repealing Directives 2001/77/EC and 2003/30/EC (Text with EEA Relavance). 2009. Available online: https:/eur-lex.europa.eu/legal-content/ EN/ALL/?uri=CELEX\%3A32009L0028 (accessed on 28 August 2020).

5. European Commission's Knowledge Centre for Bioeconomy. Brief on Biomass for Energy in the European Union; 2019; Available online: https://op.europa.eu/en/publication-detail/-/publication/7931acc2-1ec5-11e9-8d0401aa75ed71a1 (accessed on 28 August 2020). [CrossRef]

6. Calderón Cristina, C.; Colla Martin, C.; Jossart Jean-Marc, J.; Hemeleers Nathalie, H.; Cancian Giulia, C.; Aveni Nino, C.C. Statistical Report 2019, Pellet; Bioenergy Europe: Brussels, Belgium, 2019.

7. Dhamodaran, A.; Afzal, M. Compression and springback properties of hardwood and softwood pellets. BioResources 2012, 7, 4362-4376.

8. Mobini, M.; Meyer, J.C.; Trippe, F.; Sowlati, T.; Fröhling, M.; Schultmann, F. Assessing the integration of torrefaction into wood pellet production. J. Clean. Prod. 2014, 78, 216-225. [CrossRef]

9. Thek, G.; Obernberger, I. The Pellet Handbook: The Production and Thermal Utilization of Biomass Pellets, 1st ed.; Earthscan: London, UK; Washington, DC, USA, 2010; ISBN 978-1-84407-631-4.

10. van Loo, S.; Koppejan, J. The Handbook of Biomass Combustion and Co-Firing; Earthscan: London, UK; Sterling, TX, USA, 2008; ISBN 978-1-84407-249-1.

11. Lewandowski, I.; Weger, J.; van Hooijdonk, A.; Havlickova, K.; van Dam, J.; Faaij, A. The potential biomass for energy production in the Czech Republic. Biomass Bioenergy 2006, 30, 405-421. [CrossRef]

12. Valente, C.; Spinelli, R.; Hillring, B.G. LCA of environmental and socio-economic impacts related to wood energy production in alpine conditions: Valle di Fiemme (Italy). J. Clean. Prod. 2011, 19, 1931-1938. [CrossRef]

13. Sacchelli, S.; Bernetti, I.; De Meo, I.; Fiori, L.; Paletto, A.; Zambelli, P.; Ciolli, M. Matching socio-economic and environmental efficiency of wood-residues energy chain: A partial equilibrium model for a case study in Alpine area. J. Clean. Prod. 2014, 66, 431-442. [CrossRef]

14. Giuntoli, J.; Caserini, S.; Marelli, L.; Baxter, D.; Agostini, A. Domestic heating from forest logging residues: Environmental risks and benefits. J. Clean. Prod. 2015, 99, 206-216. [CrossRef]

15. Hurteau, M.; North, M. Fuel treatment effects on tree-based forest carbon storage and emissions under modeled wildfire scenarios. Front. Ecol. Environ. 2009, 7, 409-414. [CrossRef]

16. Ganguly, I.; Pierobon, F.; Bowers, T.C.; Huisenga, M.; Johnston, G.; Eastin, I.L. 'Woods-to-Wake' Life Cycle Assessment of residual woody biomass based jet-fuel using mild bisulfite pretreatment. Biomass Bioenergy 2018, 108, 207-216. [CrossRef]

17. Pierobon, F.; Eastin, I.L.; Ganguly, I. Life cycle assessment of residual lignocellulosic biomass-based jet fuel with activated carbon and lignosulfonate as co-products. Biotechnol. Biofuels 2018, 11. [CrossRef]

18. Cherubini, F.; Bird, N.D.; Cowie, A.; Jungmeier, G.; Schlamadinger, B.; Woess-Gallasch, S. Energy- and greenhouse gas-based LCA of biofuel and bioenergy systems: Key issues, ranges and recommendations. Resour. Conserv. Recycl. 2009, 53, 434-447. [CrossRef]

19. Guest, G.; Bright, R.M.; Cherubini, F.; Michelsen, O.; Strømman, A.H. Life cycle assessment of biomass-based combined heat and power plants: Centralized versus decentralized deployment strategies. J. Ind. Ecol. 2011, 15, 908-921. [CrossRef]

20. Magelli, F.; Boucher, K.; Bi, H.T.; Melin, S.; Bonoli, A. An environmental impact assessment of exported wood pellets from Canada to Europe. Biomass Bioenergy 2009, 33, 434-441. [CrossRef]

21. Fantozzi, F.; Buratti, C. Life cycle assessment of biomass chains: Wood pellet from short rotation coppice using data measured on a real plant. Biomass Bioenergy 2010, 34, 1796-1804. [CrossRef] 
22. Katers, J.F.; Snippen, A.J.; Puettmann, M.E. Life-cycle inventory of wood pellet manufacturing and utilization in Wisconsin. For. Prod. J. 2012, 62, 289-295. [CrossRef]

23. Pa, A.; Craven, J.S.; Bi, X.T.; Melin, S.; Sokhansanj, S. Environmental footprints of British Columbia wood pellets from a simplified life cycle analysis. Int. J. Life Cycle Assess. 2012, 17, 220-231. [CrossRef]

24. Hossain, M.U.; Leu, S.Y.; Poon, C.S. Sustainability analysis of pelletized bio-fuel derived from recycled wood product wastes in Hong Kong. J. Clean. Prod. 2016, 113, 400-410. [CrossRef]

25. Laschi, A.; Marchi, E.; González-García, S. Environmental performance of wood pellets' production through life cycle analysis. Energy 2016, 103, 469-480. [CrossRef]

26. Pergola, M.; Gialdini, A.; Celano, G.; Basile, M.; Caniani, D.; Cozzi, M.; Gentilesca, T.; Mancini, I.M.; Pastore, V.; Romano, S.; et al. An environmental and economic analysis of the wood-pellet chain: Two case studies in Southern Italy. Int. J. Life Cycle Assess. 2018, 23, 1675-1684. [CrossRef]

27. Quinteiro, P.; Greco, F.; da Cruz Tarelho, L.A.; Righi, S.; Arroja, L.; Dias, A.C. A comparative life cycle assessment of centralised and decentralised wood pellets production for residential heating. Sci. Total Environ. 2020, 730. [CrossRef] [PubMed]

28. Sjølie, H.K.; Solberg, B. Greenhouse gas emission impacts of use of Norwegian wood pellets: A sensitivity analysis. Environ. Sci. Policy 2011, 14, 1028-1040. [CrossRef]

29. Murphy, F.; Devlin, G.; McDonnell, K. Greenhouse gas and energy based life cycle analysis of products from the Irish wood processing industry. J. Clean. Prod. 2015, 92, 134-141. [CrossRef]

30. Buchholz, T.; Gunn, J.S.; Saah, D.S. Greenhouse gas emissions of local wood pellet heat from northeastern US forests. Energy 2017, 141, 483-491. [CrossRef]

31. Taskhiri, M.S.; Garbs, M.; Geldermann, J. Sustainable logistics network for wood flow considering cascade utilisation. J. Clean. Prod. 2016, 110, 25-39. [CrossRef]

32. Röder, M.; Whittaker, C.; Thornley, P. How certain are greenhouse gas reductions from bioenergy? Life cycle assessment and uncertainty analysis of wood pellet-to-electricity supply chains from forest residues. Biomass Bioenergy 2014, 79, 50-63. [CrossRef]

33. McManus, M.C. Life cycle impacts of waste wood biomass heating systems: A case study of three UK based systems. Energy 2010, 35, 4064-4070. [CrossRef]

34. Lippke, B.; Oneil, E.; Harrison, R.; Skog, K.; Gustavsson, L.; Sathre, R. Life cycle impacts of forest management and wood utilization on carbon mitigation: Knowns and unknowns. Carbon Manag. 2011, 2, 303-333. [CrossRef]

35. McKechnie, J.; Colombo, S.; Chen, J.; Mabee, W.; MacLean, H.L. Forest bioenergy or forest carbon? Assessing trade-offs in greenhouse gas mitigation with wood-based fuels. Environ. Sci. Technol. 2011, 45, 789-795. [CrossRef]

36. Whittaker, C.; Mortimer, N.; Murphy, R.; Matthews, R. Energy and greenhouse gas balance of the use of forest residues for bioenergy production in the UK. Biomass Bioenergy 2011, 35, 4581-4594. [CrossRef]

37. Routa, J.; Kellomäki, S.; Strandman, H. Effects of forest management on total biomass production and $\mathrm{CO}_{2}$ emissions from use of energy biomass of Norway Spruce and Scots Pine. BioEnergy Res. 2012, 5, 733-747. [CrossRef]

38. Helin, T.; Sokka, L.; Soimakallio, S.; Pingoud, K.; Pajula, T. Approaches for inclusion of forest carbon cycle in life cycle assessment-A review. GCB Bioenergy 2013, 5, 475-486. [CrossRef]

39. Levasseur, A.; Lesage, P.; Margni, M.; Deschěnes, L.; Samson, R. Considering time in LCA: Dynamic LCA and its application to global warming impact assessments. Environ. Sci. Technol. 2010, 44, 3169-3174. [CrossRef] [PubMed]

40. Cherubini, F.; Peters, G.P.; Berntsen, T.; Strømman, A.H.; Hertwich, E. $\mathrm{CO}_{2}$ emissions from biomass combustion for bioenergy: Atmospheric decay and contribution to global warming. GCB Bioenergy 2011, 3, 413-426. [CrossRef]

41. Brandão, M.; Levasseur, A.; Kirschbaum, M.U.F.; Weidema, B.P.; Cowie, A.L.; Jørgensen, S.V.; Hauschild, M.Z.; Pennington, D.W.; Chomkhamsri, K. Key issues and options in accounting for carbon sequestration and temporary storage in life cycle assessment and carbon footprinting. Int. J. Life Cycle Assess. 2013, 18, 230-240. [CrossRef]

42. Cherubini, F.; Fuglestvedt, J.; Gasser, T.; Reisinger, A.; Cavalett, O.; Huijbregts, M.A.J.; Johansson, D.J.A.; Jørgensen, S.V.; Raugei, M.; Schivley, G.; et al. Bridging the gap between impact assessment methods and climate science. Environ. Sci. Policy 2016, 64, 129-140. [CrossRef]

43. Brandão, M.; Kirschbaum, M.U.F.; Cowie, A.L.; Hjuler, S.V. Quantifying the climate change effects of bioenergy systems: Comparison of 15 impact assessment methods. GCB Bioenergy 2019, 11, 727-743. [CrossRef]

44. Ganguly, I.; Pierobon, F.; Hall, E.S. Global warming mitigating role of wood products from Washington state's private forests. Forests 2020, 11, 194. [CrossRef] 
45. ISO (International Organisation for Standardization). Norm ISO 17225-1:2014. Solid Biofuel. Fuel Specifications and Classes; Part 1: General Requirements; ISO (International Organisation for Standardization): Geneva, Switzerland, 2014.

46. ISO (International Organisation for Standardization). Norm ISO 17225-2:2014. Solid Biofuel. Fuel Specifications and Classes; Part 2: Graded Wood Pellet; ISO (International Organisation for Standardization): Geneva, Switzerland, 2014.

47. ISO (International Organisation for Standardization). ISO 14040:2006. Environmental Management-Life Cycle Assessment-Principles and Framework; ISO (International Organisation for Standardization): Geneva, Switzerland, 2006.

48. ISO (International Organisation for Standardization). ISO 14044:2006. Environmental Management-Life Cycle Assessment-Requirements and Guidelines; ISO (International Organisation for Standardization): Geneva, Switzerland, 2006.

49. Sphera Solutions GmbH. Part 1: What Is LCA, and How do You Carry out an LCA with GaBi? Available online: http://www.gabi-software.com/support/gabi-learning-center/gabi-learning-center/part-1-lca-andintroduction-to-gabi/ (accessed on 5 October 2020).

50. Guinee, J.B.; Gorrée, M.; Heijungs, R.; Huppes, G.; Kleijn, R.; de Koning, A.; van Oers, L.; Wegener Sleeswijk, A.; Suh, S.; Udo de Haes, H.A.; et al. Handbook on Life Cycle Assessment. Operational Guide to the ISO Standards. I: LCA in Perspective. IIa: Guide. IIb: Operational Annex. III: Scientific Background; Guinee, J.B., Ed.; Kluwer Academic Publishers: Dordrecht, The Netherlands, 2002; ISBN 1-4020-0228-9.

51. Frischknecht, R.; Jungbluth, N.; Althaus, H.-J.; Doka, G.; Dones, R.; Heck, T.; Al, E. The ecoinvent database: Overview and methodological framework. Int. J. Life Cycle Assess. 2005, 10, 3-9. [CrossRef]

52. Boschiero, M.; Kelderer, M.; Schmitt, A.O.; Andreotti, C.; Zerbe, S. Influence of agricultural residues interpretation and allocation procedures on the environmental performance of bioelectricity production-A case study on woodchips from apple orchards. Appl. Energy 2015, 147. [CrossRef]

53. Milota, M. CORRIM Report: Module B-Life Cycle Assessment for the Production of Pacific Northwest Softwood Lumber; 2015; Available online: https://www.corrim.org/wp-content/uploads/Module-B-PNW-Lumber.pdf (accessed on 2 October 2020).

54. Cespi, D.; Passarini, F.; Ciacci, L.; Vassura, I.; Castellani, V.; Collina, E.; Piazzalunga, A.; Morselli, L. Heating systems LCA: Comparison of biomass-based appliances. Int. J. Life Cycle Assess. 2014, 19, 89-99. [CrossRef]

55. Solli, C.; Reenaas, M.; Strømman, A.; Hertwich, E. Life cycle assessment of wood-based heating in Norway. Int. J. Life Cycle Assess. 2009, 14, 517-528. [CrossRef]

56. Pierobon, F.; Zanetti, M.; Grigolato, S.; Sgarbossa, A.; Anfodillo, T.; Cavalli, R. Life cycle environmental impact of firewood production-A case study in Italy. Appl. Energy 2015, 150, 185-195. [CrossRef]

57. Hansson, J.; Martinsson, F.; Gustavsson, M. Greenhouse gas performance of heat and electricity from wood pellet value chains-Based on pellets for the Swedish market. Biofuels Bioprod. Biorefining 2015, 9, 378-396. [CrossRef]

58. Adams, P.W.R.; Shirley, J.E.J.; McManus, M.C. Comparative cradle-to-gate life cycle assessment of wood pellet production with torrefaction. Appl. Energy 2015, 138, 367-380. [CrossRef]

59. Giuntoli, J.; Agostini, A.; Edwards, R.; Marelli, L. Solid and Gaseous Bioenergy Pathways: Input Values and GHG Emissions. Calculated According to the Methodology Set in COM(2016) 767; EUR 27215 EN, 2017; Publications Office of the European Union: Luxembourg, 2017. [CrossRef]

60. AIEL (Associazione Italiana Energia Agroforestale). Mercati\&prezzi. Available online: https://www. aielenergia.it/public/pubblicazioni/170_M_P_2-2020_ia.pdf (accessed on 2 October 2020).

61. Visser, L.; Hoefnagels, R.; Junginger, M. Wood pellet supply chain costs-A review and cost optimization analysis. Renew. Sustain. Energy Rev. 2020, 118, 109506. [CrossRef]

Publisher's Note: MDPI stays neutral with regard to jurisdictional claims in published maps and institutional affiliations. 